\title{
Textural analyses of sidescan sonar imagery from two mound provinces in the Porcupine Seabight
}

\author{
V.A.I. Huvenne ${ }^{*}$, Ph. Blondel ${ }^{\mathrm{b}}$, J.-P. Henriet ${ }^{\mathrm{a}}$ \\ a Renard Centre of Marine Geology, Krijgslaan 281, S8, B-9000 Gent, Belgium \\ b Department of Physics, University of Bath, Bath BA2 7AY, UK
}

Received 17 July 2001; accepted 7 June 2002

\begin{abstract}
Large mound structures have been discovered in the Porcupine Seabight (Northeast Atlantic) at a depth of 500$1200 \mathrm{~m}$, associated with the growth of cold-water deep-sea coral species such as Lophelia pertusa (L.) or Madrepora oculata (L.). During the Training Through Research cruise in 1997, high-resolution OREtech sidescan sonar data were acquired over two provinces of these structures. This article focuses on the presentation and quantitative interpretation of representative sections of these sidescan data from areas around the Belgica and Hovland mounds. Several image analysis tools were used, but texture analysis, based on grey level co-occurrence matrices, gave the best results. Entropy and homogeneity indices were calculated, and the resulting images made it possible to discriminate between different seabed features on a quantitative basis. Mounds, moats and background sediments could be delineated accurately, and the image textures could be linked to the actual seafloor appearance through core descriptions and deep-towed video data. A major difference was found in the acoustic returns from the two provinces studied: the Belgica province shows much rougher textures. This is due to an actual difference in seabed roughness, caused by a difference in bottom currents and sediment dynamics in the two areas. The combined effect of the northward-directed North Atlantic slope current and superimposed internal waves and tides appears to be much stronger in the Belgica province. The reported difference in current strength might well influence the growth of the deep-water coral species in both areas. (C) 2002 Elsevier Science B.V. All rights reserved.
\end{abstract}

Keywords: mounds; sidescan sonar imagery; Porcupine Seabight; cold-water corals; image analysis; grey level co-occurrence matrices

\section{Introduction}

The Porcupine Seabight is an embayment of the North Atlantic continental margin, located off SW Ireland (Fig. 1). It is a dynamic area where

* Corresponding author. Fax: +32-9-264-49-67.

E-mail address: veerle.huvenne@rug.ac.be (V.A.I. Huvenne). hydrocarbons have been found and good-quality oils have flowed from test wells (Croker and Shannon, 1995; Spencer and MacTiernan, 2001). Its sedimentary environment is characterised by drift deposits (Van Rooij et al., submitted) and channel-and-levee complexes (Kenyon et al., 1978), influenced by the northward-flowing 'slope current' which follows the North Atlantic continental slope contours (White, 2001). Within this setting, mound structures are found at three dif- 
ferent locations (Fig. 1), in water depths of 500$1200 \mathrm{~m}$. They have been identified as 'carbonate knolls' (Hovland et al., 1994), bioherms (Henriet et al., 1998) or coral banks (De Mol et al., 2002). Understanding the origin and formation mechanisms of these mounds is an important issue, due to their role as habitat for a large number of species, and because of the comparison of present-day mounds with ancient, similar structures in the geological record. But these formation controls and evolutionary pathways are still not clear, although several hypotheses concerning mound growth are presented in the literature: e.g. a possible link with methane seepage (Hovland et al., 1994), or, in some cases, with the ancient presence and decay of gas hydrates ('Magellan' mounds, Henriet et al., 1998), or the influence of oceanographic conditions on the growth and development of the associated coral species (Freiwald, 1998; De Mol et al., 2002).

To work towards solving these issues, the UNESCO-IOC Training Through Research (TTR) programme organised a multidisciplinary and multinational survey of the mound provinces in 1997 (Kenyon et al., 1998). The TTR7 cruise was organised in co-operation with the CORSAIRES and ENAM2 programmes of the European Commission. The morphology and spatial patterns of the mounds on the seabed, in particular, were studied with a high-resolution sidescan sonar. The resulting images were interpreted visually and revealed much qualitative information (e.g. Wheeler et al., in Kenyon et al., 1998). But visual, qualitative analysis should ideally be supplemented with quantitative, repeatable results. These should go as far as possible beyond what can be achieved with the unaided eye, and must be usable to bolster the different interpretations possible.

Several image analysis techniques and algorithms are now available, from the literature or as ready-made software packages. This article aims at presenting re-processed sonar imagery and its quantitative study with a range of image analysis techniques. The first objective is the quantification of the acoustic textures associated with the different geological features on the seabed and with the different mound types. The second objective is to use these measurements to throw more light on the important environmental factors influencing mound appearance, their growth and their formation.

\section{Geodynamic setting}

\subsection{The Porcupine Seabight}

The Porcupine Seabight, southwest of Ireland, extends for about $230 \mathrm{~km}$ in the north-south direction, and is $100 \mathrm{~km}$ wide at most (Masson and Miles, 1986; Fig. 1). It is bounded to the north by the Slyne Ridge, to the south by the Goban Spur, to the west by the Porcupine Bank and to the east by the Irish Shelf (Moore, 1992). Water depths range from $400 \mathrm{~m}$ in the north to more than $3000 \mathrm{~m}$ in the southwest, where the embayment opens into the Porcupine Abyssal Plain. The Seabight itself is underlain by an extensional rift basin (Porcupine Basin), one of the many deep sedimentary basins of this origin that surround Ireland (Croker and Shannon, 1995). Since the PermoTriassic, it has known a long history of extension associated with faulting and basin fill (Masson and Miles, 1986; McCann et al., 1995). The basin has been extensively studied for oil and gas exploration, but only recently has it attracted the renewed interest of the academic community, owing to the presence of cold-water deep-sea corals.

The present-day sedimentation in the area seems to be mainly pelagic and hemipelagic, with sediments becoming finer towards greater depths (Rice et al., 1991). Around $500 \mathrm{~m}$ depth, a coccolith-foraminiferal marl was described by Lampitt et al. (1986), while Swennen et al. (in Kenyon et al., 1998) also found foraminiferal sands. At $3000 \mathrm{~m}$, Tudhope and Scoffin (1995) encountered planktonic oozes, both on the floor of a channel system, on its flanks and in the surrounding areas. Over the whole area, ice-rafted glacial erratics are present, as well as clinker and coal residues. Iceberg ploughmarks were recognised on the Porcupine Bank, in water depths of 140-500 m (Belderson et al., 1973). Ever-present bioturbation generally decreases towards greater depths, although important differences in degree exist over short distances (Rice et al., 1991). 


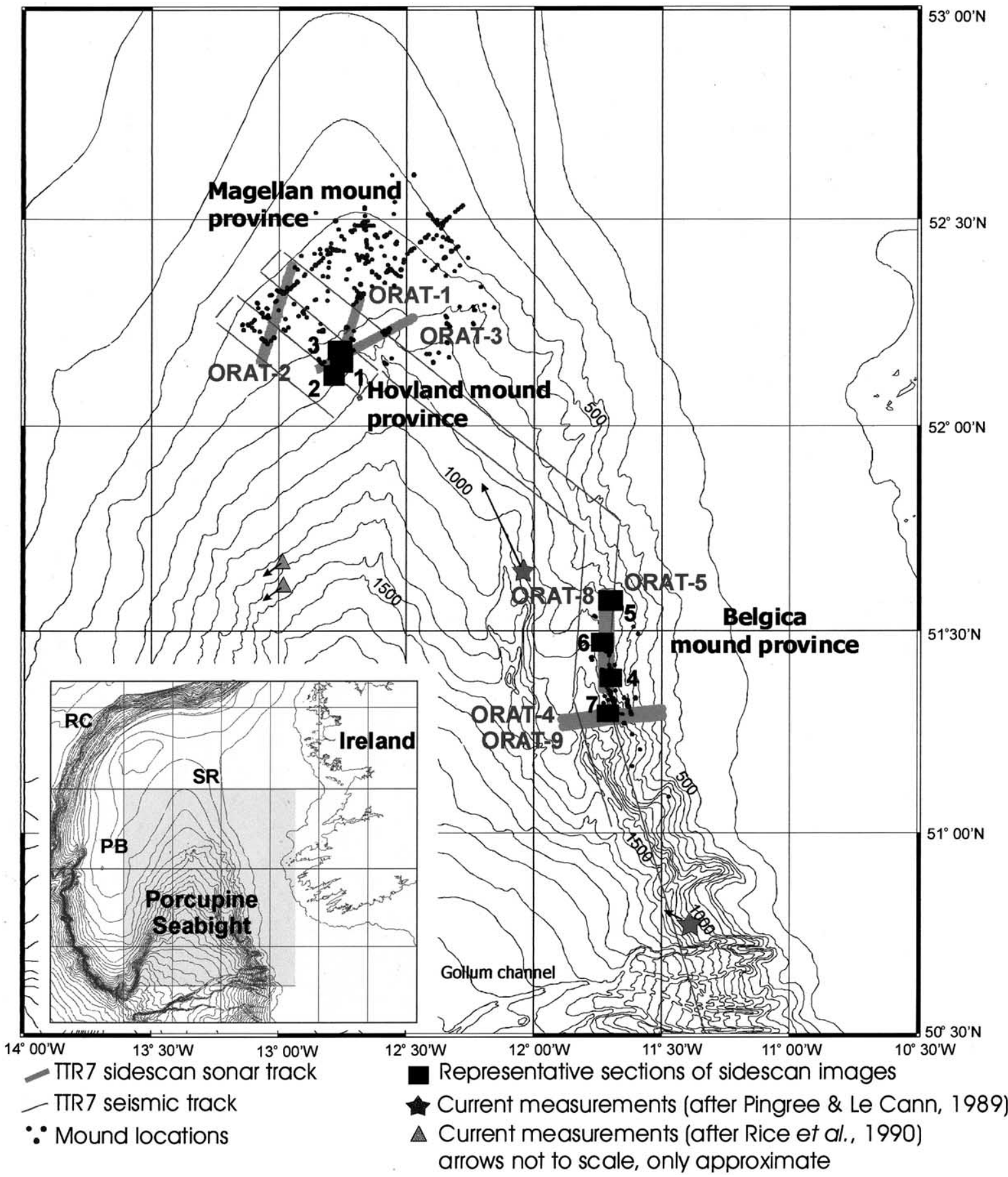

Fig. 1. Location map of the Porcupine Seabight. Bathymetric contours in metres (GEBCO, 1997). The sidescan sonar survey lines selected in this study are represented as grey lines, labelled ORAT-1 to ORAT- 9 . The representative sections analysed with Tex$A n$ are marked with black squares. Sections 2 and 3 are pictured in Figs. 2 and 6, sections 4 and 5 in Figs. 3 and 7. PB: Porcupine Bank, SR: Slyne Ridge, RC: Rockall Channel. 
The main sediment supply zone is located on the shelves (Celtic and Irish shelf), while the input from the Porcupine Bank is much smaller (Rice et al., 1991). Hence it is only along the slightly steeper eastern slope of the Porcupine Seabight $\left(2-3^{\circ}\right)$ that several channels are found (e.g. Kenyon et al., 1978). They form the upper part of the 'Gollum Channel' (Fig. 1), and seem to be inactive nowadays (Tudhope and Scoffin, 1995). Slightly to the north, and on the undissected stretches of the slope in between the channels, ridges were found, ca. $25 \mathrm{~m}$ high and on average $1.5 \mathrm{~km}$ apart. They were interpreted as slump folds, caused by downslope sediment creep (Kenyon, 1987). However, the most northerly of these structures was later recognised on high-resolution seismic records as being a province of mounds ('Belgica' province, Henriet et al., 1998).

\subsection{Regional hydrography and sediment transport}

Temperature and salinity measurements at the mouth of the Seabight revealed the water mass structure in the area (Hargreaves, 1984). The upper layer $(750 \mathrm{~m})$ of relatively warm and saline water is formed by the inflow of ENAW (Eastern North Atlantic Water) from the Bay of Biscay (Hargreaves, 1984; White and Bowyer, 1997). This layer is underlain, down to $950 \mathrm{~m}$ depth, by MOW (Mediterranean Outflow Water), characterised by a high salinity and low oxygen content. At greater depth, down to $1700 \mathrm{~m}$, the influence of Labrador Sea water is demonstrated by a salinity minimum and oxygen maximum. At about $1900 \mathrm{~m}$, traces of Norwegian Sea water are detected (Rice et al., 1991). A permanent thermocline is present at water depths of $600-1400 \mathrm{~m}$, indicated by a temperature decrease from $10^{\circ} \mathrm{C}$ to $4^{\circ} \mathrm{C}$. A seasonal thermocline forms yearly at about $50 \mathrm{~m}$ depth.

Both bottom and detached nepheloid layers, formed by high concentrations of suspended particles in the water column, are found at several places in the Porcupine Seabight (Rice et al., 1991) and west of the Porcupine Bank (Dickson and McCave, 1986). They are thought to originate from the Porcupine Bank, where they are formed through the erosion of the seabed by internal waves and tides. They detach from the seabed and move off-slope along isopycnal surfaces until a depth of some 700-800 m.

A general northward current system, called the 'slope current', is present along the eastern North Atlantic continental slope (White, 2001). This current generally follows the contours of the continental slope, although measurements at $2000 \mathrm{~m}$ depth by Rice et al. (1991) could not show if the current enters rather than bypasses the Seabight. Pingree and Le Cann (1989) found consistent northward bottom residual currents at two locations along the eastern slope in the Seabight (1000 m depth). New et al. (2001) studied the possibility of this slope current being the northward transport mechanism for the MOW. From their models, currents at the (relative) density surface of 27.60 (800-1300 m depth) seem to sweep around the Seabight, although a part of the general northward slope current bypasses it as well.

Besides these general poleward flows, there exist relatively strong diurnal and semidiurnal internal tides and associated internal waves. They are present in the areas where the shelf slope exceeds the characteristic slope defined by Huthnance (1986) as a function of the semidiurnal frequency, the Coriolis frequency at this latitude, the depth and the degree of water stratification. This is in particular the case in the eastern Porcupine Seabight, where the local slope exceeds the characteristic slope. This can result in enhanced nearbottom currents and turbulence (Pingree and Le Cann, 1990; Rice et al., 1990).

\subsection{Mound structures}

Mound structures have recently been discovered in the Porcupine Seabight, and have rapidly become a hot topic of research in the area. This is largely due to their environmental significance. They occur mainly in two areas (Fig. 1). One cluster is located along the eastern slopes (Belgica province; Henriet et al., 1998). Another cluster can be found in the northern Seabight, and has been divided into two provinces, the Magellan province and the Hovland province (Henriet et al., 1998; De Mol et al., 2002).

Each of these provinces has distinct (geo)mor- 
phological characteristics, making out three generic types of mounds. The Hovland province is mainly characterised by large mounds (average: $110 \mathrm{~m}$, but up to $150 \mathrm{~m}$ above the seafloor) placed on a relatively smooth seabed. Most mounds seem conical, and they are often linked in multiple, elongated, ridge-like structures with upper slopes varying between 10 and $25^{\circ}$. They are surrounded by irregular moat structures, scoured in the hemipelagic sediments by the local currents (De Mol et al., 2002). The Magellan mounds are very numerous and mainly buried (Huvenne et al., submitted). A few of them also protrude up from the seabed. Generally speaking, they are not as large as the Hovland mounds; average sizes of $70 \mathrm{~m}$ were estimated from commercial 3D seismics (Huvenne et al., 2001). Moats were scoured around the Magellan mounds too. Finally, the mounds in the Belgica province are placed along the slightly steeper eastern slope. They are semiburied by sediments piling up against the structures at the upslope side; at their western side they are flanked by a north-south-running channel (Van Rooij et al., submitted). They are mainly arranged en echelon, which is interpreted as evidence of the strong currents in the area (Wheeler et al., in Kenyon et al., 1998). However, clear moat structures (such as seen in the Magellan area) are not visible in this province.

Core information reveals that the mounds are composed of carbonate-rich clay containing abundant coral debris fragments. Most of them are covered with cold-water coral associations of $\mathrm{Lo}$ phelia pertusa L. and Madrepora oculata L. (Akhmetzanov et al., in De Mol et al., 1998). A more extensive description of these mound types, their seismic facies and sedimentology is given in De Mol et al. (2002). The authors also discuss the possible role of the MOW and the associated oceanographic conditions in the origin and formation history of the coral banks.

\section{Methodology}

\subsection{Sidescan sonar imagery}

Acoustic images of the seafloor in the Porcu- pine Seabight were acquired with an OREtech sidescan sonar system during the TTR7 survey (Akentieva and Shashkin, in Kenyon et al., 1998). The OREtech is a high-resolution system capable of ensonifying a swath of $2000 \mathrm{~m}(1000 \mathrm{~m}$ on either side) in its long-range mode. It was operated at a frequency of $30 \mathrm{kHz}$, recording images with a raw spatial resolution of $0.375 \mathrm{~m}$. The instrument was towed $\sim 130 \mathrm{~m}$ above the seabed and was positioned by an acoustic short-baseline underwater navigation system. Additional pitch, roll and heading sensors gave information about the attitude of the vehicle, i.e. what portion of the seafloor it was actually ensonifying.

Nine separate lines of data were recorded over the Porcupine Seabight: three lines in the northern part of the Seabight, four in its eastern part, and two over the Gollum Channel. The latter two lines are not considered here, because they do not show any mound structures. The ground track of the other lines is shown in Fig. 1. The navigation and attitude files were filtered and reprocessed to remove outliers and spikes, and the raw acoustic data were processed using PRISM (LeBas and Hühnerbach, 1998). This thorough processing followed the steps outlined in Blondel and Murton (1997): radiometric corrections (speckle removal, time-varying gain corrections), geometric corrections (e.g. slant range to ground range, anamorphosis), as well as stencilling and mosaicking. To preserve details while reducing the amount of noise present in the data, the original resolution of $0.375 \mathrm{~m}$ was reduced to $3 \mathrm{~m}$ across and along track. The dynamic range of the acoustic backscatter was fully preserved through quantisation on 256 levels (8 bits).

\subsection{Concurrent datasets}

Other instruments were used during the TTR7 survey, and their measurements in the areas ensonified by the OREtech sidescan sonar were used to further the analyses. Airgun reflection seismic data were recorded to gather some information about the sub-seafloor. The OREtech system also contained a $6-\mathrm{kHz}$ acoustic sub-bottom profiler. Point information was collected through gravity and box coring, TV-guided grab samples 
a.

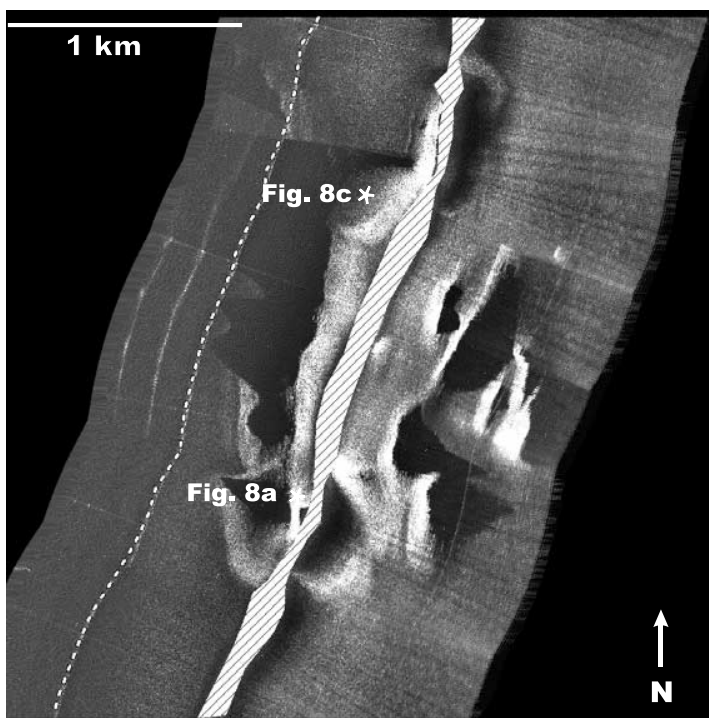

\section{..... Sea surface reflection}
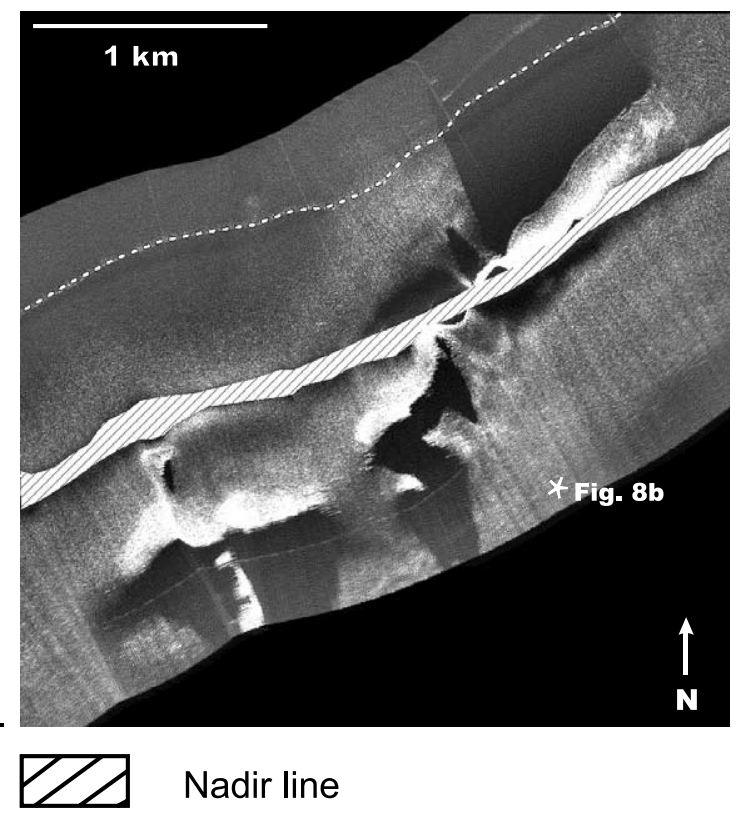

Fig. 2. (a,b) Two representative sections (sections 2 and 3) of the processed OREtech sidescan imagery, showing mound structures from the northern Seabight (Hovland province). The ground resolution is $3 \mathrm{~m}$ per pixel, and the pixel brightness is directly proportional to the acoustic backscatter (i.e. higher backscatter levels are brighter, lower backscatter levels are darker). The masked portions correspond to the nadir of the OREtech vehicle, where no useful data can be acquired.

and a few dredges in selected places. Underwater photographs and video imagery, collected from a system towed 2-8 $\mathrm{m}$ above the seabed, were used for ground-truthing in the classification and interpretation of the acoustic images. The detailed technical specifications of these instruments are given in Kenyon et al. (1998).

Profiler and seismic records provide information about the location of mounds and moats, while the core records and video images are used in refining the interpretation of the image analysis results.

\subsection{Spatial statistics and image analysis}

The processed sonar images were first interpreted visually, i.e. qualitatively. Seven distinct areas were selected for further investigation, on the basis of their coverage and complexity. Three sections contain mound structures from the northern Seabight (Hovland province) (Fig. 2a,b), while the other four sections were chosen over mounds and sedimentary structures of the eastern Seabight (Belgica province) (Fig. 3a,b).
In a general way, the different units of remotesensing images can be mapped on the basis of their tonal and textural properties. Tonal information is directly related to the amount of acoustic energy backscattered, i.e. the grey levels. Different statistical indices (e.g. extrema, median values) can be used to quantify local information. In this case the variance and skewness images were computed, using moving windows of $5 \times 5$ pixels, more or less matching the size of texturebuilding elements in the images.

These first-order statistics quantify the distribution of the grey levels, but do not take into account their positions relative to each other (i.e. the acoustic textures). Local textural properties can be intuitively qualified as rough or smooth, varied or homogeneous, repetitive or random, and hence can help in distinguishing between different areas and features in the images. Quantitative textural measurements (second-order statistics) can be extracted from the image with various techniques, the most efficient ones being stochastic (e.g. Haralick, 1979). In this study, we used non-directional edgeness, calculated with the So- 

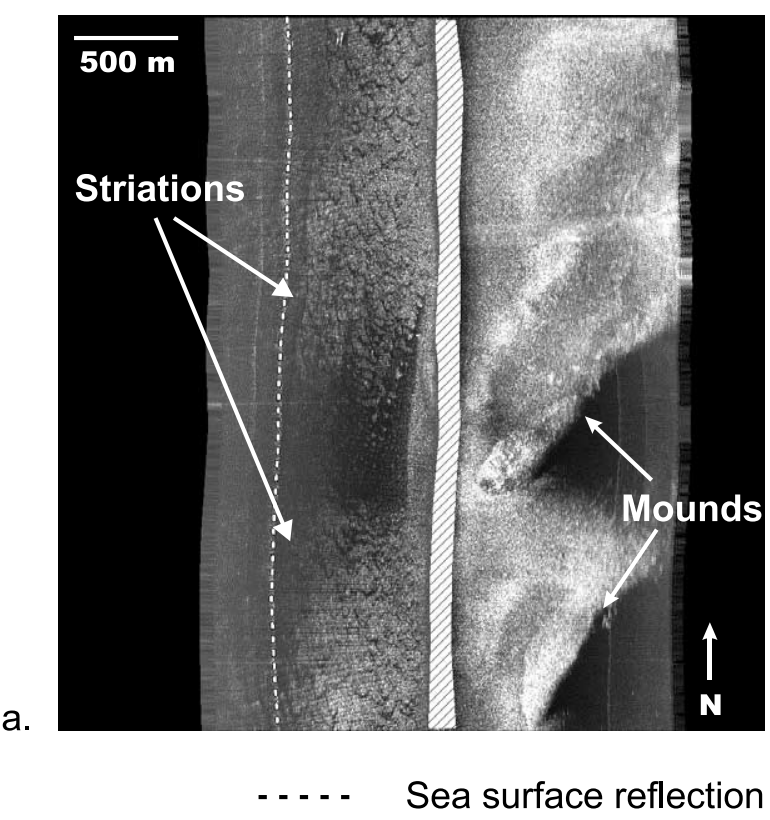

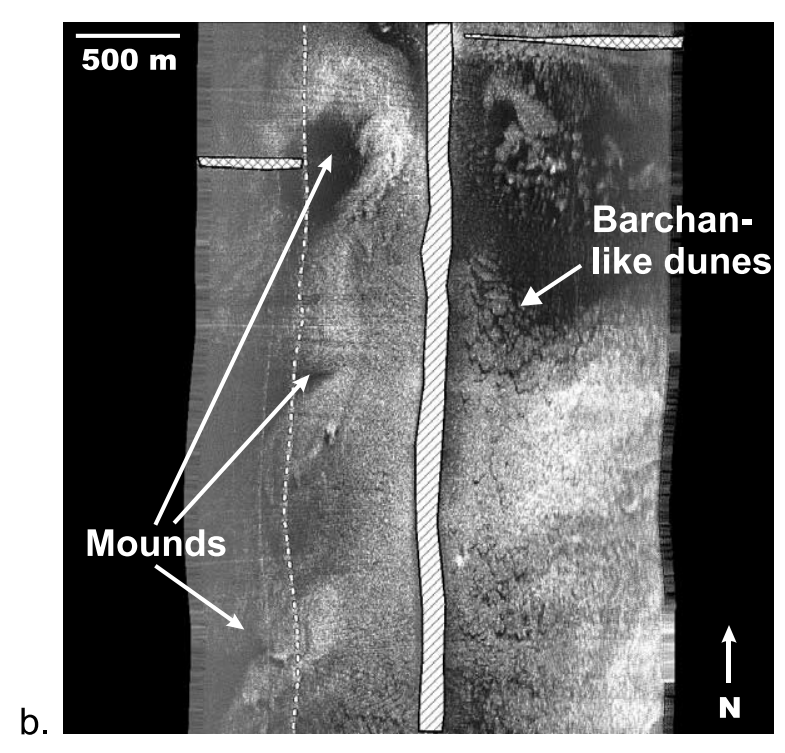

Nadir line

Fig. 3. (a,b) Two representative sections (sections 4 and 5) of the processed OREtech sidescan imagery, showing the mounds and some sedimentary structures of the eastern Seabight (Belgica province). Ground resolution and pixel brightness convention are equal to those in Fig. 2.

bel algorithm (Pratt, 1978); the edgeness per unit area; two-dimensional Fourier transforms; and textural entropy and textural homogeneity computed from grey-level co-occurrence matrices (GLCMs; Blondel, 1996).

The edgeness per unit area was computed over windows of $19 \times 19$ pixels, to be comparable to the windows of $20 \times 20$ pixels and $40 \times 40$ pixels used for co-occurrence matrices. The edgeness estimates the number of edges (sharp changes in grey level) per unit area (e.g. Pratt, 1978). The more of these sharp changes are present, the rougher the texture will be. Edges are detected through algorithms based on the calculation of the second-order derivative in all directions, or the convolution of the image with specific kernels which smooth homogeneous areas and enhance contrasts at boundaries.

Natural textures are much more complex than artificial textures, and their Fourier transforms generally do not provide clearly interpretable results (e.g. Russ, 1994). This was indeed the case here, and the effect is probably enhanced by acoustic noise and by the physics of the imaging process. Therefore Fourier transforms were not considered any further. The other techniques, using both first- and second-order statistics, were compared with principal component analysis. This shows that the textural entropy and homogeneity, computed with GLCMs in moving windows of $20 \times 20$ pixels, best describe the texture and image variability. This is consistent with previous analyses performed on similarly high-resolution sidescan sonar imagery, like DSL-120 data (1-m resolution: Blondel et al., 1993) or TOBI data (6-m resolution: Blondel, 1996). The technique and its results are detailed in 4. Textural analysis of sonar imagery.

\section{Textural analysis of sonar imagery}

\subsection{Textural analysis}

Textures can be quantified in different ways, but theoretical work by Haralick (1979) and practical applications to sonar imagery by Reed and Hussong (1989), Blondel et al. (1993), Blondel 
(1996, 2000), Gao et al. (1998) and others have shown that co-occurrence matrices are the most adapted tools. Co-occurrence matrices address the average spatial relationships between pixels of a small region. Experiments on human vision (Julesz, 1973, in Blondel, 1996) demonstrated that the eye could not distinguish between textures with different second-order statistics, proving GLCMs could be used to go further than traditional, visual interpretation alone.

The textural information in the image is described by a set of co-occurrence matrices $\left\{P_{\boldsymbol{D}}(i, j)\right\}$. Each element $P_{\boldsymbol{D}}(i, j)$ expresses the relative frequency of occurrence of two points, with the respective grey levels $i$ and $j$, at $\boldsymbol{D}(d, \theta)$ (Euclidean distance $d$ and angle $\theta$ ) from one another. If the image is quantified with NG grey levels, the GLCMs will be $\mathrm{NG} \times \mathrm{NG}$ arrays. They are computed on finite windows. The distance $\boldsymbol{D}(d, \theta)$ between pixels is very sensitive to the orientation $\theta$. This is particularly true for sidescan sonar images, in which the insonification angle varies across track, but also along track because of the movements from the sonar platform (roll, pitch, yaw). Two identical structures may be imaged with distinct look angles, and their textural signatures appear different. To ensure that the textural indices of any non-isotropic texture are not significantly influenced by the angle at which it is ensonified, the co-occurrence matrices are averaged for angles $\theta=0^{\circ}, 45^{\circ}, 90^{\circ}$, and $135^{\circ}$, following Reed and Hussong (1989) and Blondel (1996). The only computational parameters are now the inter-pixel displacement $d$, the size of the computation window and the number of grey levels.

Co-occurrence matrices are not easy to interpret directly, and they are more effectively described by statistical measures called indices. More than 25 textural indices are available from the current literature, and rigorous evaluations of their performance in the specific case of high-resolution sonar images has been performed by Blondel et al. (1993) and Blondel (1996), in conjunction with extensive ground-truth data. These evaluations revealed that two indices (entropy and textural homogeneity) are sufficient for sidescan sonar interpretation, as they can explain nearly all the textural variations (e.g. Blondel et al.,
1993; Blondel, 1996). Entropy measures the lack of spatial organisation inside the computation window. It will be high for rough textures, and low when the texture is more homogeneous or smoother, or contains organised heterogeneities (e.g. ripples). Textural homogeneity indicates the amount of local similarities within the chosen area. Some authors also refer to it as the inverse-difference moment (Gao et al., 1998). Textural homogeneity is higher for regions with a uniform backscatter (containing only a few grey levels). Because of the high sensitivity of GLCMs to linear combinations of the grey levels, additional factors were introduced by Blondel et al. (1993) to ensure invariance if time-varying or angle-varying gains change from one computation window to the next. The general texture processing has been incorporated into a software called TexAn (for Textural Analysis) (e.g. Blondel, 2000).

Repeated tests showed that the optimal separation between textural units was achieved by computing entropy and homogeneity in moving windows of $20 \times 20$ pixels. The total ranges of homogeneity and entropy values (0-255) were each divided into 25 bins. The two-dimensional entropy-homogeneity space (or feature space) is described by a look-up table (Figs. 4 and 5), in which each combination of homogeneity and entropy is assigned a class number. A combined image' was created for each of the seven selected sonar images, in which each pixel received the appropriate class number corresponding to its homogeneity and entropy values (Figs. 6 and 7). Finally these combined images were investigated in order to classify seabed features such as mounds, moats and background sediments.

\subsection{Acoustic textures in the Hovland province}

Preliminary analyses (the direct visual interpretation, and the first-order statistics) already show a major difference in appearance between the seabeds of the northern and the eastern Porcupine Seabight (Hovland versus Belgica provinces). The mean and standard deviation of the grey levels of the images from the Belgica area are much higher than for the Hovland province. Therefore both provinces will be discussed separately. 

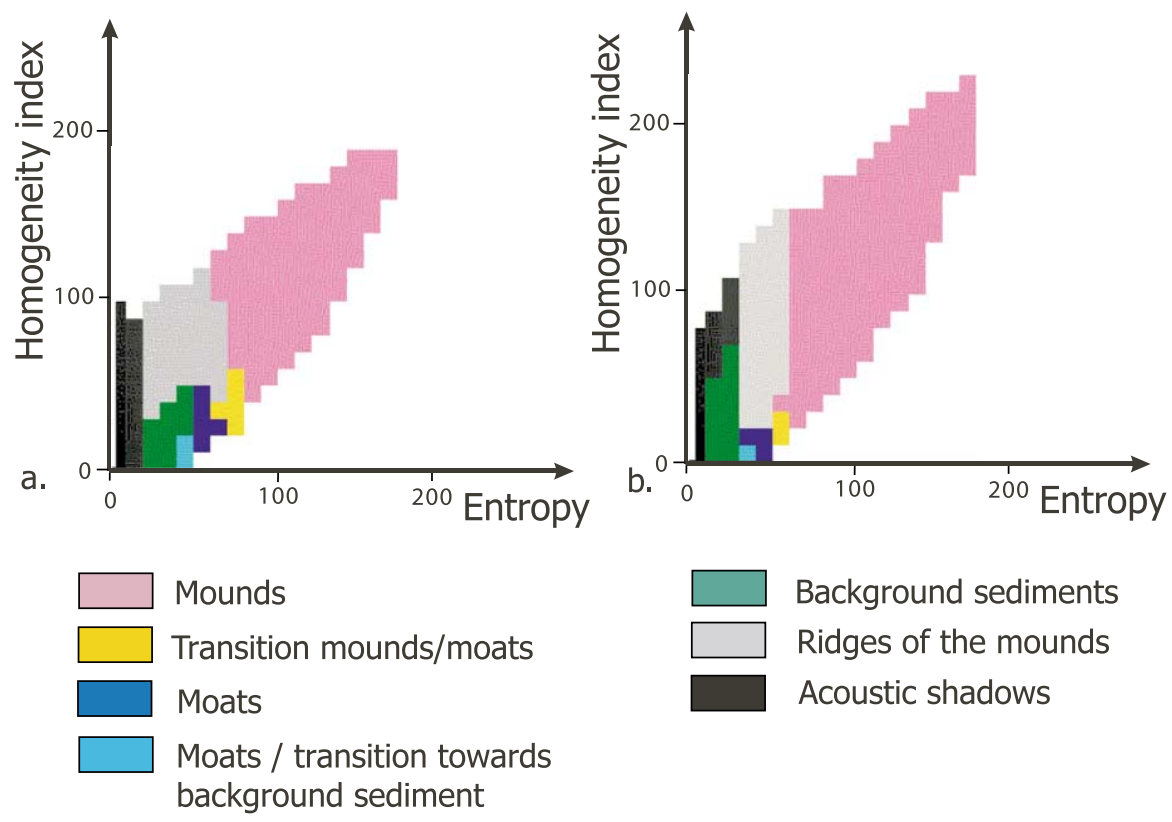

Fig. 4. (a,b) Look-up tables (or feature space graphs) of the images presented in Fig. 2a,b.

Features in the images of the northern Porcupine Seabight such as mounds, moats and background sediments are fairly easy to recognise visually (Fig. 2). Their entropy/homogeneity signatures correspond to well-delineated classes, as visible in the corresponding look-up table (Fig. 4), although it is still necessary to define narrow transition classes as well. Mounds have the highest entropy and homogeneity indices (note that the homogeneity index is a reversed
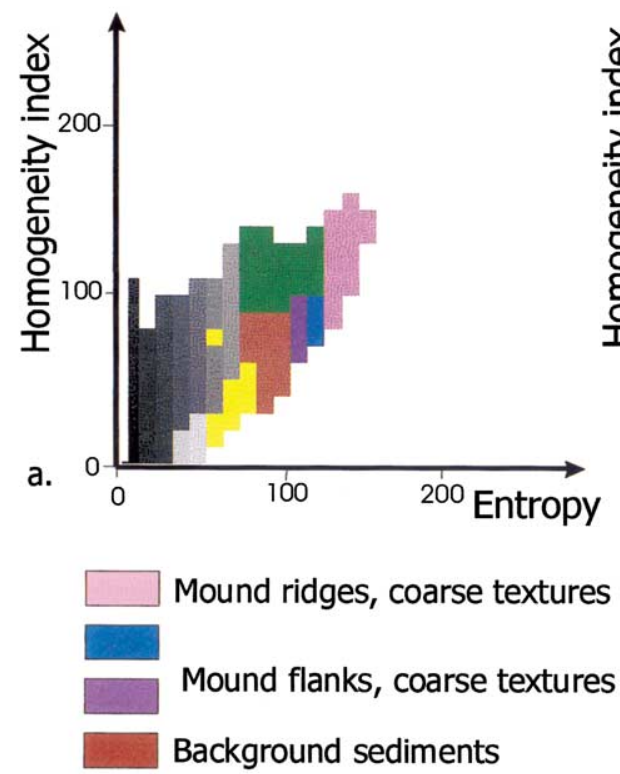

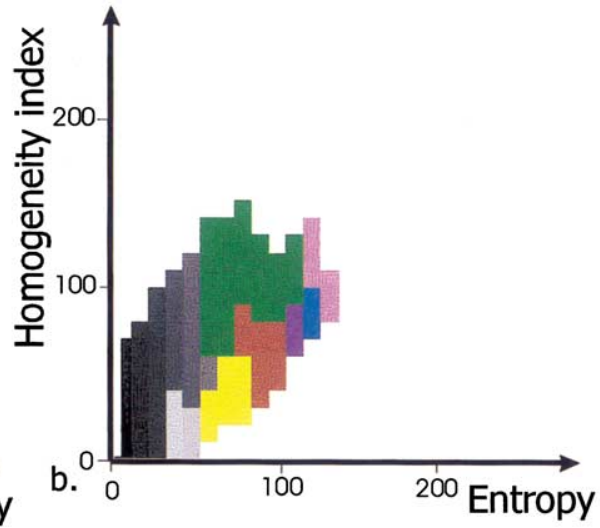

Background sediments/ transition towards shadows Acoustic shadows Artefacts

Fig. 5. (a,b) Look-up tables (or feature space graphs) of the images presented in Fig. 3a,b. 


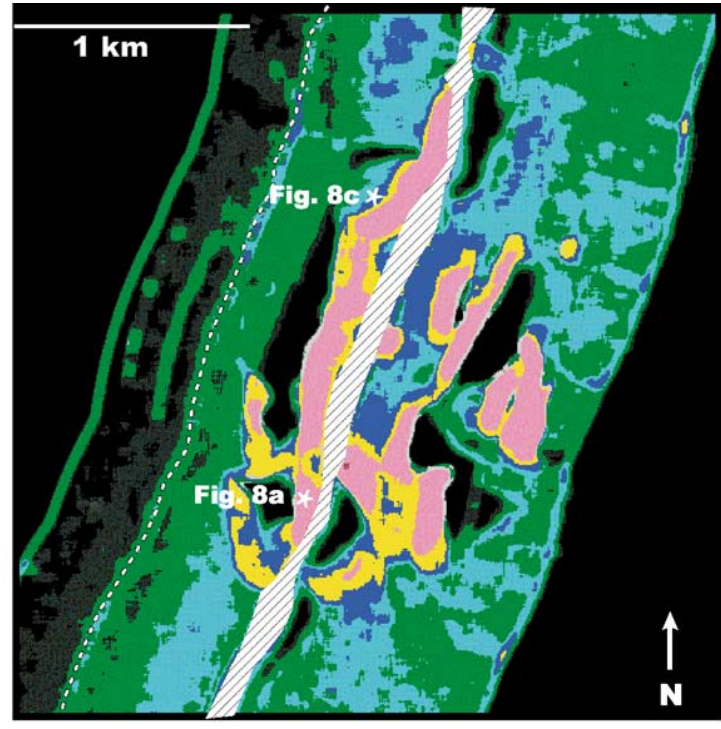

- . - - Sea surface reflection

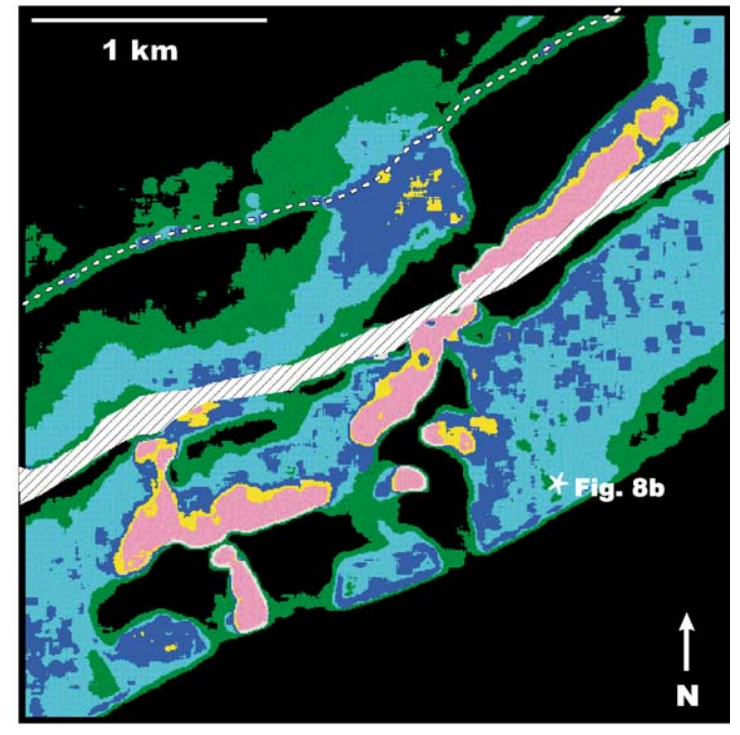

Nadir line

Fig. 6. (a,b) Classified and interpreted results of the sidescan sonar images shown in Fig. 2. The classification is based on the entropy and homogeneity texture indices calculated from the original images, and on the look-up tables presented in Fig. 4. The colour coding is the same as the one used in Fig. 4.
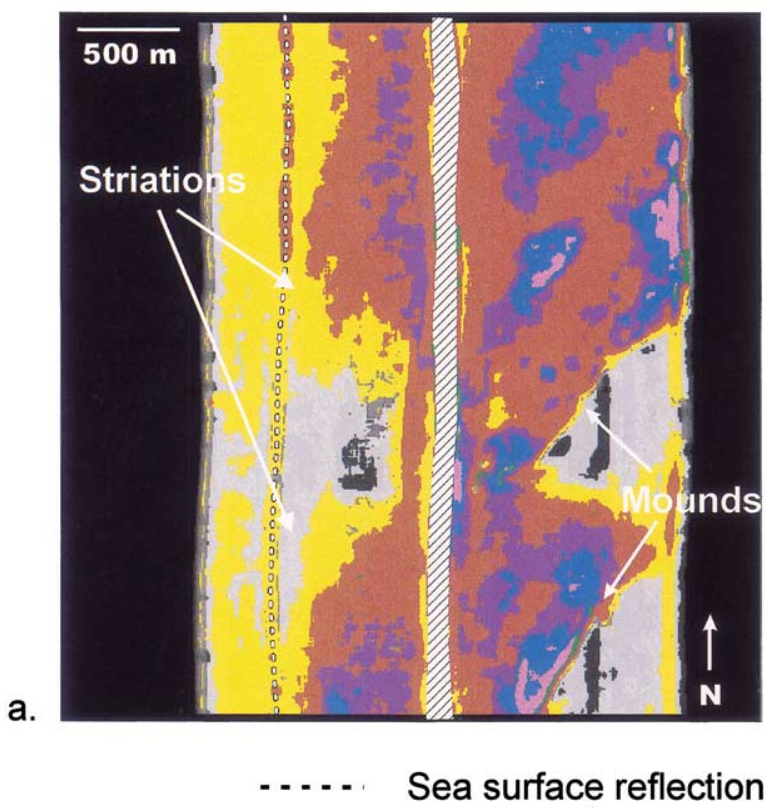

b.
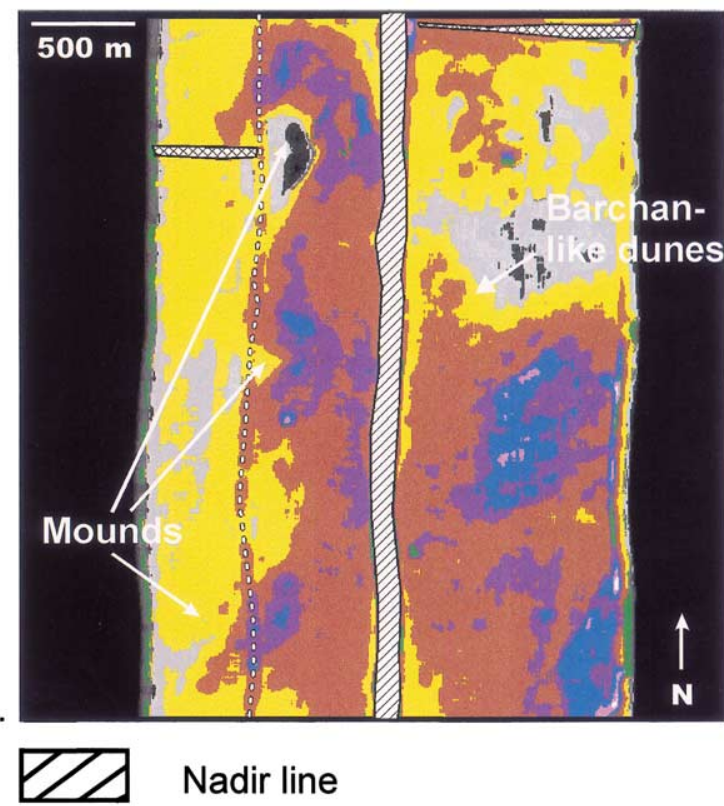

Fig. 7. (a,b) Classified and interpreted results of the sidescan sonar images shown in Fig. 3. The classification is based on the entropy and homogeneity texture indices calculated from the original images, and on the look-up tables presented in Fig. 5. The colour coding is the same as the one used in Fig. 5. 


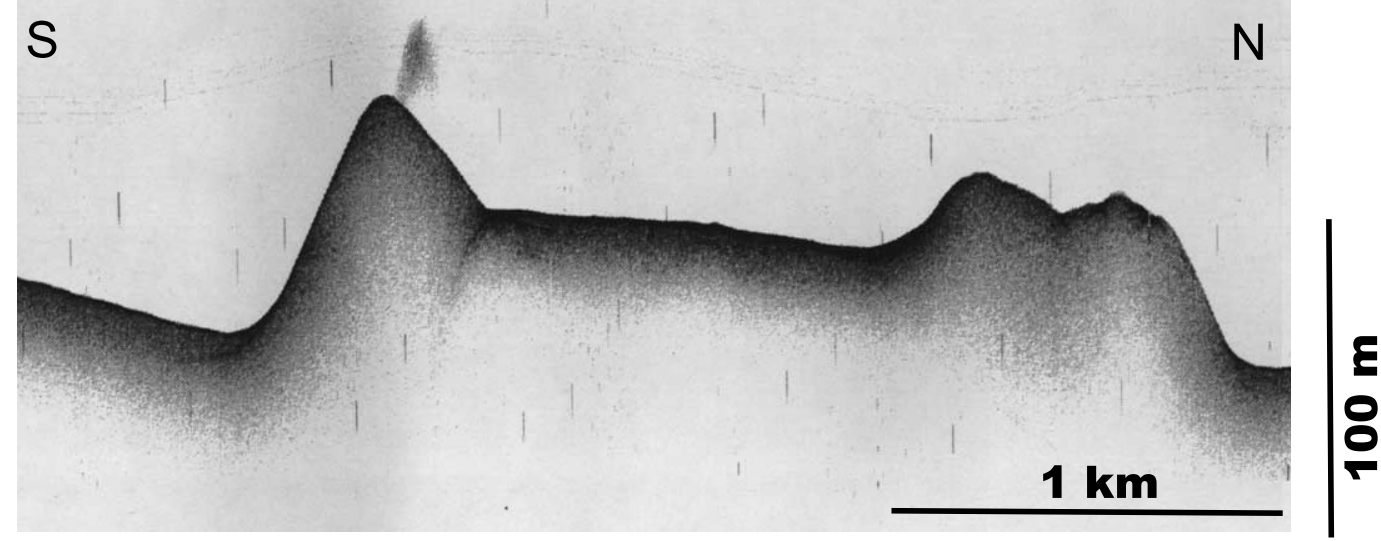

a.

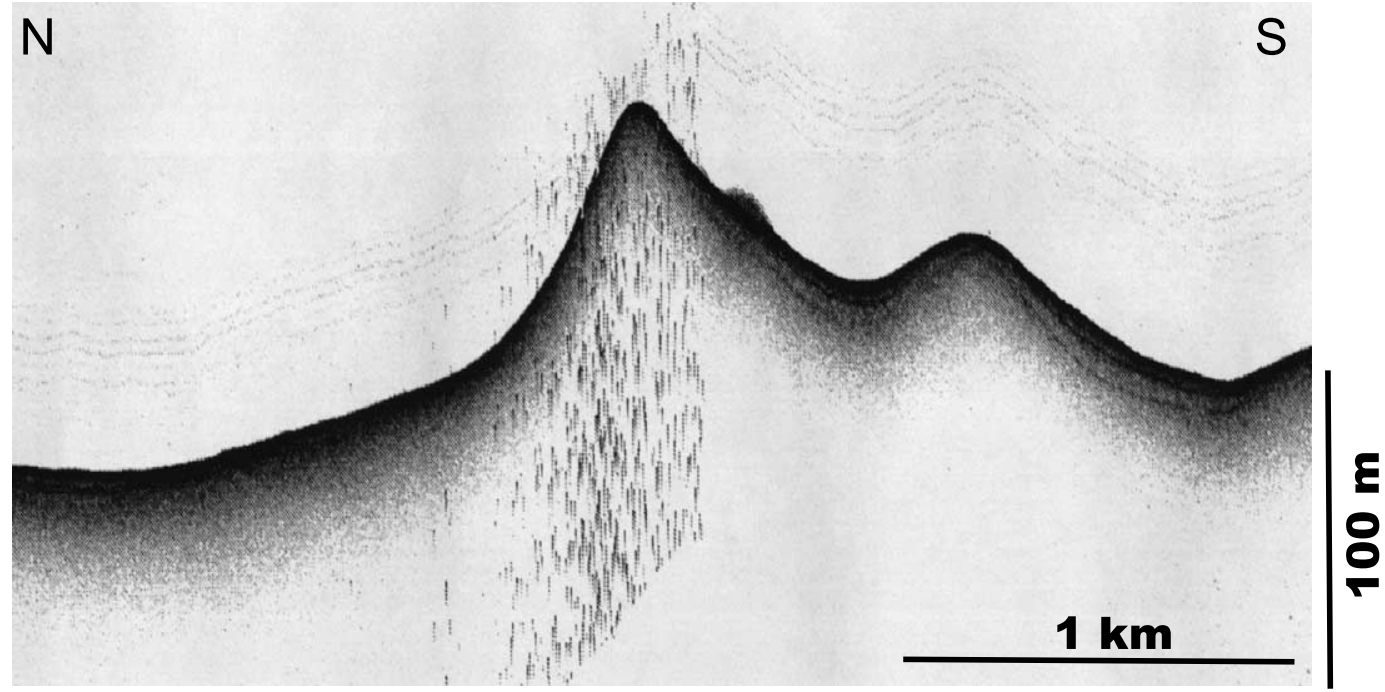

b.

Fig. 8. Sub-bottom profiler (6-kHz) seabed profiles across (a) a Hovland mound and (b) a Belgica mound. Profile (a) follows the nadir of the sidescan sonar image pictured in Fig. 2a, and hence nearly follows the ridge of the mound structure. Profile (b) does not correspond to Fig. $3 a$ or $b$, because none of these crosses a mound along its nadir line. Hence the profile was taken from another part of the sidescan sonar tracks, and is shown as an illustration of the appearance on sub-bottom profiles of a Belgica mound.

indicator: high values indicate low homogeneities and vice versa). Mounds therefore contain the roughest textures, they are characterised by a wide range of entropy and homogeneity values. Due to saturation effects, the human eye would not recognise these textures as consisting of a large number of grey levels (and hence being in- homogeneous). Because of their orientation (slope towards the instrument), the mound slopes also have the brightest reflections (in high contrast with the surroundings), within which the human eye cannot easily recognise differences. However, the TexAn software can identify the inhomogeneity. 
a.

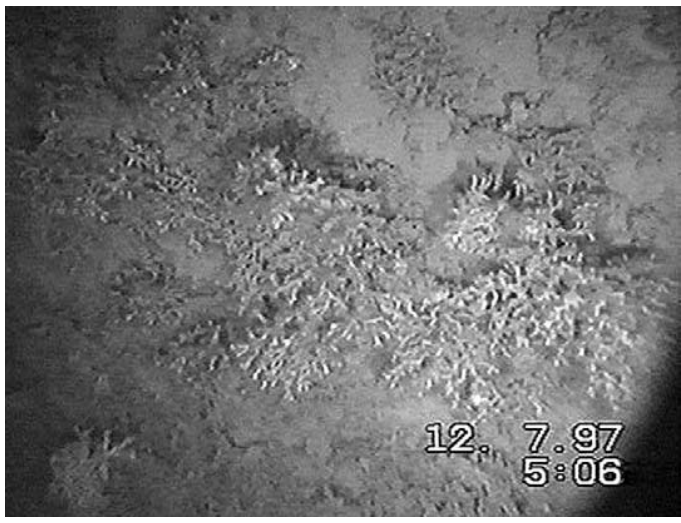

C.

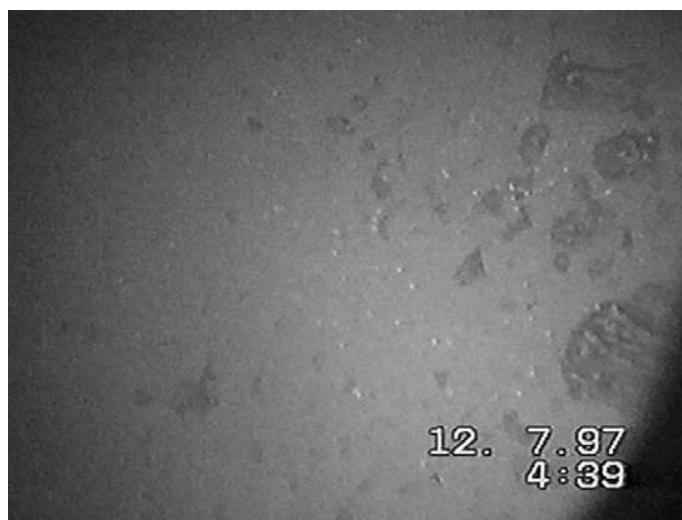

b.

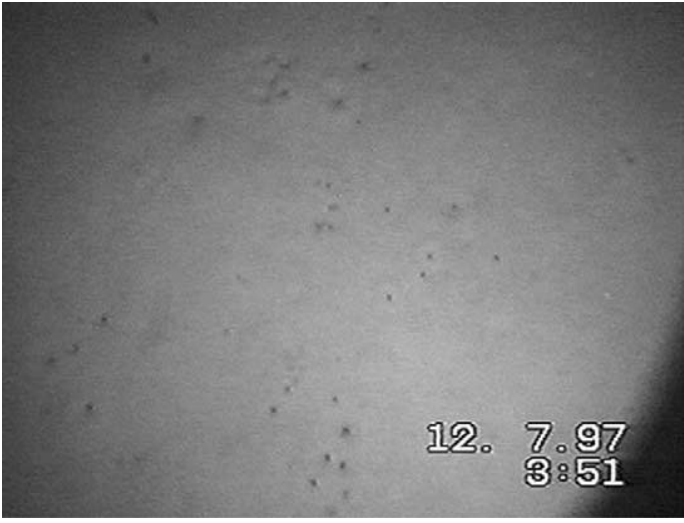

d.

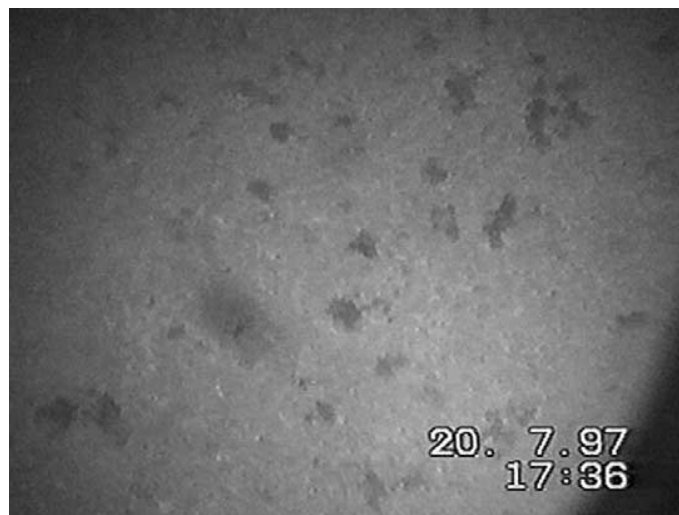

Fig. 9. Selection of photographs from the TTR7 deep-tow video (locations indicated in Figs. 2 and 6). (a) Coral association on the flank of a Hovland mound, picturing Lophelia pertusa L. (b) Smooth, bioturbated seabed (background sediments) in the Hovland province. (c) Seabed appearance in the moat of a Hovland mound. (d) Coarser-textured background sediments on the seafloor of the Belgica province.

The sonar and textural images show the mounds as elongated structures and multiple ridges (Figs. 2 and 5), extending more than 2.5 $\mathrm{km}$ in length and $250-400 \mathrm{~m}$ in width, generally tending NE-SW. From profiler data, they are estimated to reach around $110 \mathrm{~m}$ in height above the seabed (Fig. 8a). Mounds have the roughest image textures, due to the presence of coral debris and of what seem to be carbonate crusts or dropstones, but mainly because of the occurrence of corals and their associated fauna. This can be seen clearly from the seabed video (Fig. 9a), and is also reported from the core descriptions (e.g. cores TTR7-AT-5G, 14G and 17G, Table 1). An extra factor causing the roughness is the patchiness of the coral associations. Their acoustic re- turns create irregular patterns, resulting in a large number of grey levels, arranged in unorganised patches within small neighbourhoods of the images, and hence with a low homogeneity (high homogeneity index) and a high entropy (Fig. 4).

Compared to the mounds, the sediments are much smoother (lower entropy and homogeneity values) and mainly have a much smaller entropy range (Fig. 4). This is due to the actual smoothness of the sediments on the seabed, inducing little or no variations in the acoustic returns. In the core descriptions (TTR7-AT-9G, 11G, 12G and $13 \mathrm{G})$, the seabed for these locations is described as water-rich marl, or sometimes even 'soupy' clay (Swennen et al., in Kenyon et al., 1998). The seabed video shows hemipelagic muddy sediments 
Table 1

Core descriptions from the TTR7 cruise (from Swennen et al., in Kenyon et al., 1998)

\begin{tabular}{|c|c|c|c|c|c|}
\hline Province & Core & Latitude & Longitude & Location & Description of upper horizon \\
\hline Hovland & TTR7-AT-5G & $52^{\circ} 13.99$ & $12^{\circ} 43.38$ & mound & coarse carbonate sand with corals at the top \\
\hline Hovland & TTR7-AT-6G & $52^{\circ} 13.67$ & $12^{\circ} 43.56$ & moat & foraminiferal sand/marl; some lithic and shell fragments \\
\hline Hovland & TTR7-AT-9G & $52^{\circ} 12.73$ & $13^{\circ} 02.38$ & $\begin{array}{l}\text { background } \\
\text { sediments }\end{array}$ & $\begin{array}{l}\text { greyish brown carbonate clay rich in forams with some shell } \\
\text { fragments }\end{array}$ \\
\hline Hovland & TTR7-AT-11G & $52^{\circ} 12.72$ & $13^{\circ} 02.46$ & $\begin{array}{l}\text { background } \\
\text { sediments }\end{array}$ & light olive brown liquified mud with high foram content \\
\hline Hovland & TTR7-AT-12G & $52^{\circ} 16.40$ & $13^{\circ} 00.42$ & $\begin{array}{l}\text { background } \\
\text { sediments }\end{array}$ & $\begin{array}{l}\text { foraminiferal light olive brown to dark brown silt; tube of } \\
\text { Polychaeta found at the top of the core }\end{array}$ \\
\hline Hovland & TTR7-AT-13G & $52^{\circ} 19.19$ & $12^{\circ} 59.07$ & $\begin{array}{l}\text { background } \\
\text { sediments }\end{array}$ & soupy foraminiferal silty marls \\
\hline Hovland & TTR7-AT-14G & $52^{\circ} 18.88$ & $12^{\circ} 40.70$ & mound & $\begin{array}{l}\text { branching corals in foraminiferal silt matrix; rare dropstone } \\
\text { present }\end{array}$ \\
\hline Hovland & TTR7-AT-17G & $52^{\circ} 08.72$ & $12^{\circ} 49.15$ & mound & $\begin{array}{l}\text { silt with high foraminiferal content; shell and coral fragments } \\
\text { present }\end{array}$ \\
\hline Belgica & TTR7-AT-33G & $51^{\circ} 18.00$ & $11^{\circ} 39.19$ & $\begin{array}{l}\text { background } \\
\text { sediments }\end{array}$ & soupy brownish foraminiferal sand, coarse-grained \\
\hline Belgica & TTR7-AT-36G & $51^{\circ} 23.14$ & $11^{\circ} 42.17$ & $\begin{array}{l}\text { background } \\
\text { sediments }\end{array}$ & $\begin{array}{l}\text { coarse sand, yellow-orange in colour; live animal/intact } \\
\text { Polychaeta tube; forams }\end{array}$ \\
\hline
\end{tabular}

with a high degree of bioturbation (Fig. 9b). No ripples, sandwaves or other current-induced bedforms or irregularities can be observed on the seabed.

The textural signature of the moats, scoured in the seabed around the mounds, lies somewhere between that of the mounds and the sediments, and is restricted to a very narrow range of entropies and homogeneities (Fig. 4). Transition classes towards mound and sediment textures sometimes need to be defined. However, a texture typical of the geological feature can be delineated in the image, which would be difficult to achieve directly from visual analysis. It can be seen that the shapes of the moats are fairly irregular, and that they are not as well developed on all sides of the mounds. Interpreted from the video images, it seems that the moats contain slightly coarser materials than the background sediments in the area (Fig. 9c). The seafloor seems sandier, containing dropstones and coarse fragments, while no bioturbation can be seen. This is most probably due to current scouring and a limited amount of bed armouring, which can leave sandier materials in the scour marks while sweeping away the finest sediments (Gomez, 1983). Another factor of influence may be the presence of some coral or shell fragments distributed off the mounds by the cur- rents. The only core taken in a moat (TTR7-AT6G) seems to confirm this interpretation ('foraminiferal sand/marl with some lithic and shell fragments', Table 1). These coarser materials clearly increase the entropy of the acoustic returns, but the homogeneity index stays as low as for the background sediments (Fig. 4). Really inhomogeneous, irregular image textures are only found amongst the coral patches on the mounds.

The look-up table (Fig. 4) shows that a relatively large interval of homogeneities and a restricted interval of entropies are not directly assigned to a geological feature. They correspond in fact to a class called 'ridges'. This contains the few pixels which form a transition between mound surfaces and shadow zones: areas of rapid change in smoothness and organisation, with their own textural signature.

Comparing the classification results from different sections of the same province, the same textural patterns can be seen in the look-up tables (Fig. 4a v. 4b). They are sometimes shifted over at most 10 entropy or homogeneity units. This shows the general consistency of the algorithm and of the textural signatures, although these small differences could cause misclassifications, for example of moats, in automated (unsupervised) classifications. The cause of these shifts 
is not clear; they may be related to a different direction of ensonification of the mounds, to different water conditions during the recording, or to unaccounted changes in the acquisition settings.

\subsection{Acoustic textures in the Belgica province}

Textural analyses of the images from the eastern Porcupine Seabight do not provide such a clear and immediate interpretation (Fig. 7). There is a gradation in entropy and homogeneity again, but areas that can be interpreted as mounds have a smaller and lower entropy range than in the Hovland province. Their textural signatures are not unique any more: some areas, which can be interpreted as sand fields or moats, contain similar or even higher entropy and homogeneity values. But mounds still show a coarse texture, caused by the patchy growth of coral colonies. This creates a micro-topography which can give coral colonies a 'cauliflower' appearance in sidescan sonar images, especially at very high resolutions (e.g. Milkert and Hühnerbach, 1997; Freiwald et al., 1999).

Acoustic artefacts present in all sonar images are reflections from the sea surface (visible as a continuous high-backscatter line) and near-nadir areas, in which the backscatter does not have any physical significance (e.g. Blondel and Murton, 1997). These artefacts present very high entropies and homogeneities, with values close to the textural indices of mounds. They correspond to sharp changes in grey levels and hence show an irregular texture. The artefacts are easily recognisable as such on the original image, and can be either masked during TexAn processing, or removed through advanced post-processing (e.g. within PRISM). They were kept in the images presented here, for completeness and to show how textural analysis was reacting to these abrupt changes.

The mounds in the eastern Porcupine Seabight seem to consist mainly of single structures nearly $1 \mathrm{~km}$ long, placed en echelon on a few $\mathrm{N}-\mathrm{S}$ lines and having their main axes oriented in a NNESSW direction. Moats are not present around every mound, as can be seen from the profiler data, for example (Fig. 8). When present, these moats often correspond to very high grey levels, and high entropy and homogeneity indices. They certainly have higher grey levels and texture indices than the moats in the northern area.

Background sediments, identified from their sonar appearance corroborated by video images, present textures with entropy values much higher (60-80 units higher on a scale of $0-255)$ than the background sediments of the northern Porcupine Seabight (Figs. 4 and 5). Cores taken in these rougher sediments are described as 'soupy' foraminiferal sands or coarse sands (pelagic cores TTR7-AT-33G, 36G, Table 1). From the video (Fig. 9d) it is clear that these sediments are indeed coarser. Stones and sometimes even coral debris are present on the seabed, which is not the case in the northern area. In some cases the seabed seems nearly gravelly, while in other cases bedforms such as ripples or dunes are developed (Wheeler et al., in Kenyon et al., 1998). They will greatly influence the sonar returns, introducing backscatter values different from the ones usually expected from smooth sediments. These variations will in turn induce textural variations. Another parameter which was not explicitly quantified in the core descriptions, but which is likely to play an important role in the different acoustic returns as well, is the change in the sediments' porosity and density.

\section{Discussion}

Textural analysis with TexAn quantified the major differences in the acoustic and geological character of the seabed in the northern and eastern Porcupine Seabight (Hovland and Belgica provinces). In the Belgica province, the sediments and the background seabed are rougher, the mounds are slightly smaller and they consist of single structures often placed en echelon. The textural difference between different features (mounds, moats, sediments) is much less pronounced. Other features such as striation patterns, barchan-like dunes and sandwaves can be seen in some parts of the sidescan sonar data. These features are not present in the Hovland province. 
Here the seabed is much smoother, thus emphasising even more the distinct roughness of the mound surfaces and moats. Mounds in this province can be lined up in ridges, or can consist of multiple structures. The main differences between the Hovland and Belgica provinces therefore seem to be the character of the sediments, and the characteristics of the mounds.

The principal reason for the difference in acoustic appearance between the two provinces is the recent current regime at the seabed, and the associated sediment dynamics. Pingree and Le Cann (1989) measured average current speeds of $2.5 \mathrm{~cm} /$ $\mathrm{s}$ and $11.0 \mathrm{~cm} / \mathrm{s}$ at $8 \mathrm{~m}$ above the seabed, immediately south and north of the Belgica province $\left(50^{\circ} 47.4^{\prime} \mathrm{N}, 11^{\circ} 24.5^{\prime} \mathrm{W}\right.$ and $51^{\circ} 40.5^{\prime} \mathrm{N}, 12^{\circ} 02.6^{\prime} \mathrm{W}$, Fig. 1). In both cases, flows were in a northward direction. Bathysnap measurements described by Rice et al. (1990) on the western flank of the Seabight show current speeds varying between 1 and $3 \mathrm{~cm} / \mathrm{s}$, mainly directed to the southwest (Fig. 1). According to the hydrographic models of New et al. (2001), the residual currents in the area should follow the depth contours and sweep around the Porcupine Seabight. Similar conclusions were drawn by White (2001) from available current meter data west of Ireland: bottom currents in the Porcupine Seabight seem to follow the depth contours, but the measurements in the Hovland province show the lowest current stability and speeds.

Besides these general currents, the existence of internal tides and waves and breaking internal waves was mentioned by several authors (e.g. Pingree and Le Cann, 1990; Rice et al., 1991). Rice et al. (1990) mapped the locations in the Porcupine Seabight where the seabed slope exceeds the characteristic slope, and found that the area described here as the Belgica province is prone to these effects. At these locations, internal tides are generated in the continuously stratified waters by the interaction of the across-slope barotropic tide with the shelf break (New and Pingree, 1990). The stratification is even enhanced at this depth (c. $750 \mathrm{~m}$ ) due to the contact between the water masses of the ENAW and the MOW, each with their own density. This all results in an intensification of the (near-bottom) tidal currents and the induction of large oscillations of the water particles (due to some form of resonance with their natural frequency) (Rice et al., 1990). Because of non-linear effects and breaking of the internal tides on the steep slopes and shallow waters of the shelf, also internal waves of higher frequency are generated, which can locally enhance or reduce turbulence and energy dissipation (New, 1988). The occurrence of rougher sediments in the Belgica area could therefore be explained by this presence of locally enhanced current systems. They would increase the resuspension of fine particles, leaving the coarser ones on the seabed. The presence of ripple marks and striation patterns on the sonar images brings the stronger currents in evidence, while the two directions of striation show the influence of the two superimposed currents: the slope current and the tidal influences. Present-day strong current action seems to be absent from the Hovland province, as is witnessed by the hemipelagic muddy sediments and the large amount of bioturbation visible on the seabed.

Concerning the presence of internal waves, Frederiksen et al. (1992) found that Lophelia colonies around the Faeroes seemed to be linked to areas where the seabed slope exceeded the critical value, and enhanced near-bottom tidal currents were present. The breaking internal tides would influence resuspension at the seabed, and create an enhanced primary production in the associated soliton zones at the sea surface. Both effects could increase the food supply for the coral colonies. However, they also state that Lophelia is not restricted to only these areas of internal tide generation. This seems to be the case in the Hovland province, for example.

Current regime in general, and current speed in particular, are considered as very important environmental parameters influencing the growth of Lophelia organisms. The corals preferably grow in high-current areas with enhanced turbulence, such as ridge crests (Freiwald et al., 1997) or the up-current ends and tops of lithoherms, where streamlines are compressed (Messing et al., 1990). The higher current velocities would enhance the food supply for these suspension feeders (Freiwald et al., 1997). However, Frederiksen et al. (1992) state that higher current speeds do not al- 
ways mean enhanced food supply, because the food particle concentration also plays a role.

Besides their influence on food supply, Wilson (1979) also discusses the importance of current speeds for the internal dynamics of the Lophelia colonies. High or variable currents should be able to break off parts and branches of the corals, which then can form a new substrate for (re)colonisation. Sometimes whole 'coppices' break off or collapse onto the mounds (Freiwald et al., 1999). It is possible that these help to construct the 'cauliflower' structures seen on certain sonar images. The coral 'rubble' and debris also could be spread over the seafloor in areas where currents are strong enough, such as the Belgica province, causing the coarser-textured surroundings of the mounds to develop. As the presence of hard settling grounds (boulders, dropstones, large shells, coral debris, etc.) is another of the prerequisites of Lophelia growth (Rogers, 1999), this could also be one of the reasons for the more scattered presence of the corals in the Belgica province.

Currents can also influence the amount of sediment trapped inside the coral framework. They can help to prevent the living corals from silting over (Frederiksen et al., 1992). In this way there could be a difference in dynamics between the two provinces as well, although further research is necessary to establish these processes.

\section{Conclusion}

The objectives of this article were two-fold: first, to present processed sidescan sonar imagery from important mound provinces in the Porcupine Seabight; second, to show how image analyses could be used to bolster and quantify the interpretations of these images.

After a brief reminder of the geological and environmental importance of the Porcupine Seabight area, we presented high-resolution sidescan sonar imagery recently acquired with the $30-\mathrm{kHz}$ OREtech sidescan sonar, during the Training Through Research cruise TTR7 (Kenyon et al., 1998). This dataset was accurately reprocessed using the PRISM software (LeBas and Hühnerbach, 1998), yielding a fully geo-referenced acoustic im- age of the seafloor in the area. Different image analysis techniques were tried, but qualitative and quantitative comparisons showed that the best one was textural analysis based on GLCMs, using the TexAn software (Blondel, 1996).

Combined entropy/homogeneity images obtained with the TexAn classification show that there is a clear difference between the acoustic character of the northern and eastern Porcupine Seabight (Hovland and Belgica provinces). In the Hovland province, mounds, moats and background sediments can clearly be delineated from acoustic textures alone. Mounds are the roughest, because of the presence of coral fragments and living corals on the seabed, causing an irregular relief. Background sediments in the Hovland province are mainly muds, forming a smooth seafloor. Moat textural signatures are intermediate between the textural signatures of mounds and background sediments. In the Belgica province, the textural signatures are in general rougher and more complicated to interpret. Coarser sands, dropstones and bedforms induce higher entropies and homogeneities in the images. Background sediments and moats sometimes have rougher textures than mounds. Mounds cannot always be easily distinguished from the background sediments, using only the classified images.

The difference between both provinces is most probably caused by a difference in current regimes. The mean (residual) current at this depth (500-1000 m) seems to follow the depth contours, but secondary current systems are superimposed. The generation of internal tides in the Belgica province could enhance the currents there and influence the resuspension of sediments. The local current regime is very important for Lophelia colonies. It influences their food supply directly and indirectly, and can influence colony stability. Hence, both sites could exhibit distinct dynamics of mound growth, although further research is necessary to establish and confirm these differences. Long-term deployment of current meters or ADCPs at selected sites in these two areas would be essential for settling this point.

The work presented here is but one facet of the multidisciplinary research necessary to understand the complex but unique dynamics and environ- 
ment of the coral communities and mound structures, currently being discovered along the continental margins. This is nonetheless an important facet, as it demonstrates the importance of local currents in the system, and as it gives an overview of the phenomenon, and an idea of the different circumstances within which these structures can occur.

The statistical techniques, and particularly the textural analysis with TexAn, made a complete, quantitative interpretation possible. This interpretation can be replicated with similar results on any part of the dataset, or performed on any other dataset; it represents a common basis for quantitative, repeatable and reliable image analysis.

Other facets of this ongoing research are now under investigation. In particular, the integrated study of high-resolution 2D and (commercial) 3D seismics of the Magellan province brings more detailed insights into these processes (Huvenne et al., 2001). It is only once all these pieces are brought together that a complete image of these enigmatic structures can be built, and that parallels with similar structures now being discovered around the world's ocean can be made.

\section{Acknowledgements}

The sidescan sonar and video images presented in this article were collected during cruise TTR7 of the IOC/UNESCO 'Training Through Research' Programme (July-August 1997), in co-operation with the CORSAIRES and ENAM2 programmes of the European Commission. They were accessed as part of the CORSAIRES programme (MAS3-CT45-0045), coordinated by J.P.H. We would like to thank the TTR7 participants both for the high quality of the different datasets, and for the many informal discussions. Preliminary studies were performed while V.A.I.H. was a student in the School of Ocean and Earth Sciences, Southampton (UK). We warmly thank T. LeBas (SOC, UK) for adapting the PRISM software to enable us to process the OREtech data and V. Hühnerbach for his assistance. B. De Mol, D. Van Rooij and especially P. Van Rensbergen (all three from RCMG) are gratefully acknowledged for their contributions to the early stages of this article and M. Faure Didelle for the extraction of the digital photos from the video. The authors would also like to thank Dr. D.J.W. Piper (Editor-in-Chief), Dr. A. Freiwald (University of Tübingen, Germany) and Dr. N.H. Kenyon (SOC, UK) for their constructive comments which helped to improve the manuscript. V.A.I.H. is a $\mathrm{PhD}$ student funded by the FWO-Flanders (Belgium).

\section{References}

Belderson, R.H., Kenyon, N.H., Wilson, J.B., 1973. Iceberg ploughmarks in the northeast Atlantic. Palaeogeogr. Palaeoclimatol. Palaeoecol. 13, 215-224.

Blondel, P., 1996. Segmentation of the Mid-Atlantic Ridge south of the Azores, based on acoustic classification of TOBI data. In: MacLeod, C.J., Tyler, P.A., Walker, C.L. (Eds.), Tectonic, Magmatic, Hydrothermal and Biological Segmentation of Mid-Ocean Ridges. Geol. Soc. Spec. Publ. 118, 17-28.

Blondel, P., 2000. Automatic mine detection by textural analysis of COTS sidescan sonar imagery. Int. J. Remote Sensing 21, 3115-3128.

Blondel, P., Murton, B.J., 1997. Handbook of Seafloor Sonar Imagery. PRAXIS-Wiley, Chichester, $314 \mathrm{pp}$.

Blondel, P., Sempéré, J.-C., Robigou, V., 1993. Textural analysis and structure-tracking for geological mapping: Applications to sonar data from Endeavour Segment, Juan de Fuca Ridge. Proc. OCEANS'93, IEEE-OES, Victoria, BC, pp. 209-213.

Croker, P.F., Shannon, P.M., 1995. The petroleum geology of Ireland's offshore basins: introduction. In: Croker, P.F., Shannon, P.M. (Eds.), The Petroleum Geology of Ireland's Offshore BAsins. Geol. Soc. Spec. Publ. 93, 1-8.

De Mol, B., Swennen, R., Henriet, J.-P., Bouriak, S., McDonnel, A., Pillen, S., Van Rooij, D. (Eds.), 1998. Carbonate mud mounds and cold water reefs: deep biosphere-geosphere coupling. TTR-7 postcruise meeting-conference, 711 February 1998, Gent, Belgium, Abstracts book. University of Gent, Gent, 117 pp.

De Mol, B., Van Rensbergen, P., Pillen, S., Van Herreweghe, K., Van Rooij, D., McDonnell, A., Huvenne, V., Ivanov, M., Swennen, R., Henriet, J.-P., 2002. Large deep-water coral banks in the Porcupine Basin, southwest of Ireland. Mar. Geol. 188 (2002) 193-231.

Dickson, R.R., McCave, I.N., 1986. Nepheloid layers on the continental slope west of Porcupine Bank. Deep-Sea Res. 33, 791-818.

Frederiksen, R., Jensen, A., Weesterberg, H., 1992. The distribution of the scleractinian coral Lophelia pertusa around the Faroe Islands and the relation to internal tidal mixing. Sarsia $77,157-171$. 
Freiwald, A., Henrich, R., Pätzold, J., 1997. Anatomy of a deep-water coral reef mound from Stjernsund, West Finnmark, northern Norway. In: James, N.P., Clarke, J.A.D. (Eds.), Cool-Water Carbonates. SEPM Spec. Publ. 56, 141-162.

Freiwald, A., 1998. Geobiology of Lophelia pertusa (Scleractinina) Reefs in the North Atlantic. Thesis, Universität Bremen, Bremen, $110 \mathrm{pp}$.

Freiwald, A., Wilson, J.B., Henrich, R., 1999. Grounding Pleistocene icebergs shape recent deep-water coral reefs. Sediment. Geol. 125, 1-8.

Gao, D., Hurst, S.D., Karson, J.A., Delaney, J.R., Spiess, F.N., 1998. Computer-aided interpretation of side-looking sonar images from the eastern intersection of the Mid-Atlantic Ridge with the Kane Transform. J. Geophys. Res. 103 (B9), 20997-21014.

GEBCO, 1997. 1997 Edition of the IOC/IHO General Bathymetric Chart of the Oceans. GEBCO digital atlas (GDA). British Oceanographic Data Centre, Bidston Observatory, Merseyside.

Gomez, B., 1983. Temporal variations in the particle size distribution of surficial bed material: the effect of progressive bed armouring. Geogr. Ann. 65A, 183-192.

Haralick, R.M., 1979. Statistical and structural approaches to texture. Proc. IEEE 67, 786-804.

Hargreaves, P.M., 1984. The distribution of Decapoda (Crustacea) in the open ocean and near-bottom over an adjacent slope in the northern north-east Atlantic Ocean during autumn 1979. J. Mar. Biol. Assoc. UK 64, 829-857.

Henriet, J.-P., De Mol, B., Pillen, S., Vanneste, M., Van Rooij, D., Versteeg, W., Croker, P.F., Shannon, P.M., Unnithan, V., Bouriak, S., Chachkine, P., the Porcupine-Belgica 97 shipboard party, 1998. Gas hydrate crystals may help build reefs. Nature 391, 648-649.

Hovland, M., Croker, P.F., Martin, M., 1994. Fault-associated seabed mounds (carbonate knolls?) off western Ireland and northwest Australia. Mar. Pet. Geol. 11, 232-246.

Huthnance, J.M., 1986. The Rockall slope current and shelfedge processes. Proc. R. Soc. Edinburgh 88B, 83-101.

Huvenne, V., Blondel, P., Henriet, J.-P., 2001. Current influences on mound structures in the Porcupine Seabight Results from image analysis. Geophys. Res. Abstr. 3, 9322.

Huvenne, V.A.I., De Mol, B., Henriet, J.-P., submitted. A 3D seismic study of the morphology and spatial distribution of buried coral banks in the Porcupine Basin, SW of Ireland. Mar. Geol.

Kenyon, N.H., 1987. Mass-wasting features on the continental slope of Northwest Europe. Mar. Geol. 74, 57-77.

Kenyon, N.H., Belderson, R.H., Stride, A.H., 1978. Channels, canyons and slump folds on the continental slope between southwest Ireland and Spain. Oceanol. Acta 1, 369-380.

Kenyon, N.H., Ivanov, M.K., Akhmetzhanov, A.M. (Eds.), 1998. Cold Water Carbonate Mounds and Sediment Transport on the Northeast Atlantic Margin. IOC Technical Series, 52, UNESCO, $178 \mathrm{pp}$.

Lampitt, R.S., Billett, D.S.M., Rice, A.L., 1986. Biomass of the invertebrate megabenthos from 500 to $4100 \mathrm{~m}$ in the northeast Atlantic Ocean. Mar. Biol. 93, 69-81.

LeBas, T.P., Hühnerbach, V., 1998. PRISM: Processing of Remotely-sensed Imagery for Seafloor Mapping. A Collection of Software for the Processing, Analysis and Enhancement of Sidescan Sonar Imagery. SOC Technical Report, Southampton, $76 \mathrm{pp}$.

Masson, D.G., Miles, P.R., 1986. Structure and development of Porcupine Seabight sedimentary basin, offshore southwest Ireland. Am. Assoc. Pet. Geol. Bull. 70, 536-548.

McCann, T., Shannon, P.M., Moore, J.G., 1995. Fault styles in the Porcupine Basin, offshore Ireland: tectonic and sedimentary controls. In: Croker, P.F., Shannon, P.M., (Eds.), The Petroleum Geology of Ireland's Offshore Basins. Geol. Soc. Spec. Publ. 93, 371-383.

Messing, C.G., Neumann, A.C., Lang, J.C., 1990. Biozonation of deep-water lithoherms and associated hardgrounds in the northeastern Straits of Florida. Palaios 5, 15-33.

Milkert, D., Hühnerbach, V., 1997. Coastal environments. In: Blondel, P., Murton, B.J. (Eds.), Handbook of Seafloor Sonar Imagery. Praxis-Wiley, Chichester, pp. 193-221.

Moore, J.G., 1992. A syn-rift to post-rift transition sequence in the Main Porcupine Basin, offshore western Ireland. In: Parnell, J. (Ed.), Basins on the Atlantic Seaboard: Petroleum Geology, Sedimentology and Basin Evolution. Geol. Soc. Spec. Publ. 62, 333-349.

New, A.L., 1988. Internal tidal mixing in the Bay of Biscay. Deep-Sea Res. 35A, 691-709.

New, A.L., Pingree, R.D., 1990. Evidence for internal tidal mixing near the shelf break in the Bay of Biscay. DeepSea Res. 37, 1783-1803.

New, A.L., Barnard, S., Herrmann, P., Molines, J.-M., 2001. On the origin and pathway of the saline inflow to the Nordic Seas: insights from models. Prog. Oceanogr. 48, 255-287.

Pingree, R.D., Le Cann, B., 1989. Celtic and Armorican slope and shelf residual currents. Prog. Oceanogr. 23, 303-338.

Pingree, R.D., Le Cann, B., 1990. Structure, strength and seasonality of the slope currents in the Bay of Biscay region. J. Mar. Biol. Assoc. UK 70, 857-885.

Pratt, W.K., 1978. Digital Image Processing. Wiley, Chichester, $750 \mathrm{pp}$.

Reed, T.B., Hussong, D., 1989. Digital image processing techniques for enhancement and classification of SeaMARC II side scan sonar imagery. J. Geophys. Res. 94 (B6), 7469 7490.

Rice, A.L., Thurston, M.H., New, A.L., 1990. Dense aggregations of a hexactinellid sponge, Pheronema carpenteri, in the Porcupine Seabight (northeast Atlantic Ocean), and possible causes. Prog. Oceanogr. 24, 179-196.

Rice, A.L., Billet, D.S.M., Thurston, M.H., Lampitt, R.S., 1991. The Institute of Oceanographic Sciences biology programme in the Porcupine Seabight: background and general introduction. J. Mar. Biol. Assoc. UK 71, 281-310.

Rogers, A.D., 1999. The biology of Lophelia pertusa (Linnaeus 1758) and other deep-water reef-forming corals and impacts from human activities. Int. Rev. Hydrobiol. 84, 315406. 
Russ, J.C., 1994. The Image Processing Handbook, 2nd edn. CRC Press, London, 674 pp.

Spencer, A.M., MacTiernan, B., 2001. Petroleum systems offshore western Ireland in an Atlantic margin context. In: Shannon, P.M., Haughton, P.D.W., Corcoran, D.V. (Eds.), The Petroleum Exploration of Ireland's Offshore Basins. Geol. Soc. London Spec. Publ. 188, 411-438.

Tudhope, A.W., Scoffin, T.P., 1995. Processes of sedimentation in Gollum Channel, Porcupine Seabight: submersible observations and sediment analyses. Trans. R. Soc. Edinburgh Earth Sci. 86, 49-55.

Van Rooij, D., De Mol, B., Huvenne, V., Ivanov, M., Henriet,
J.-P., submitted. Seismic evidence of current-controlled sedimentation in the Belgica mound province, southwest of Ireland. Mar. Geol.

White, M., Bowyer, P., 1997. The shelf-edge current northwest of Ireland. Ann. Geophys. 15, 1076-1083.

White, M., 2001. Hydrography and Physical Dynamics at the NE Atlantic Margin that Influence the Deep Water Cold Coral Reef Ecosystem. EU ACES-ECOMOUND internal report, Department of Oceanography, NUI, Galway, $31 \mathrm{pp}$. Wilson, J.B., 1979. 'Patch' development of the deep-water coral Lophelia pertusa (L.) on Rockall Bank. J. Mar. Biol. Assoc. UK 59, 165-177. 